\title{
Cholecalciferol level and its impact on COVID-19 patients
}

\author{
Mohammed Abdel Monem Saeed ${ }^{1 *}$, Alaa Hussein Mohamed $^{2}$ and Ahmed Hassan Owaynat ${ }^{3}$
}

\begin{abstract}
Background: Cholecalciferol is an important nutrient and essential to build body, maintain strong bones, and improves immunity.

The main source for vitamin $\mathrm{D}$ is the body's skin which absorbs the sun's ultraviolet rays and convert them into vitamin D; at the same time, deficiency can occur or people may not get enough supplementation; this occurs mainly in old age, not taking healthy food, or have darker skin, and this deficient cases can raise the risk of severe COVID-19 if infected.

Vitamin D boosts immunity and decreases inflammation. Poorer outcome of corona virus—disease (COVID-19) has been suggested to be due to vitamin D deficiency.

We suggested to find the effect of cholecalciferol levels 25-hydroxy vitamin D (25 OHD) on the severity and mortality in patients suffering from COVID-19.

Methods: Our study is a prospective following of 414 patients admitted in Helwan University Hospitals in the period of June 2020 till October 2021 for severely symptomatic. COVID-19 patients with median of age $54.55 \pm 14.27$, with a definite range of APACHE II score ranging from 15 to 19 where we measured vitamin $D_{3}$ level (cholecalciferol level), correlating the assay level to the inflammatory cytokine storm markers on admission, on the fifth day and after 10 days also the level of vitamin $D_{3}$ was correlated to the length of stay mechanical ventilation days and mortality.
\end{abstract}

Results: Lower level of vitamin $D_{3}$ on admission was strongly evident in patients with severely symptomatic and in mortality of COVID-19 patients $58.25 \pm 24.59 \mathrm{nmol} / \mathrm{L}$ when compared with patients who survived $103.97 \pm 36.14$ nmol/L with $P$ value $<0.001$

Also, when correlating the initial level of vitamin $D_{3}$ on admission with the level of the inflammatory cytokine storm markers on admission, on fifth day from admission and on the tenth day, it shows a strong inverse correlation between vitamin $D_{3}$ level on admission and ferritin level on fifth day $\rho-0.739 p$ value $<0.001$ also on the tenth day $\rho-0.885$, $P$ value $<0.001$, in comparing also with $D$-dimer on fifth day $\rho-0.858, p$ value $<0.001$ also showing a strong inverse correlation with a highly significant $p$ value this also evident on the $D$-dimer level on the tenth day $\rho-0.889$ with $p$ value $<0.001$, CRP at fifth and tenth day $\rho-0.868, P$ value $<0.001, \rho-0.891, P$ value $<0.001$ respectively also in correlating the LDH level on the fifth and tenth day with the initial level of vitamin $D_{3}$ it shows a strong inverse correlation with a highly significant $p$ value. $\rho-0.887, P$ value $<0.001, \rho-0.878, p$ value $<0.001$ respectively, in the fifth and tenth day. Neutrophil to lymphocyte ratio was strongly, inversely correlated to the vitamin $\mathrm{D}_{3}$ level (cholecalciferol) on admission with $\rho-0.753, p<0.001, \rho-0.882, P<0.001$ respectively. Also, chest computed tomography in the fifth and

\footnotetext{
*Correspondence: Mohammedicu1@gmail.com

${ }^{1}$ Critical Care Medicine Department, Faculty of Medicine Helwan

University, Helwan, Egypt

Full list of author information is available at the end of the article
} 
tenth day of admission showed a very strong inverse correlation with vitamin D level and a highly significant statistical difference $\rho-0.655, p$ value $<0.001$ respectively.

Length of stay and mechanical ventilation days were also strongly inversely correlated to the cholecalciferol level $\rho-0.795, p<0.001, \rho-0.879, P<0.001$ ROC curve of vitamin $D_{3}$ to predict mortality (RR $0.865,95 \%$ Cl $0.828-0.896, P$ $<0.001$, with cut off-value for vit. $D_{3}<60 \mathrm{nmol} / \mathrm{L}$, regardless of other factors like age, gender, and presence of other co-morbidities.

Conclusion: Low level of cholecalciferol was strongly inversely correlated with cytokine storm markers and independent predictor of severity and mortality in COVID-19 patients.

Keywords: Vitamin $D_{3}$ (cholecalciferol), COVID-19, Cytokine storm markers, Chest computed tomography, Mortality

\section{Background}

Millions of individuals have been killed by SARS-Cov 2 leading to a great depression; also, it broadly varies from benign to fatal. Severe corona virus disease can be presented by interstitial pneumonia progressing to acute respiratory distress syndrome (ARDS) and respiratory failure ending in death or other co-morbidities. Pneumonia can progress to severe acute respiratory failure which will need invasive mechanical ventilation with prevalence up to $95 \%$ of respiratory distress this is evident in patients who died from the disease [1].

The imbalance of the host immune system is the main determinant of the SARS-Cov-2 outcome [2-4].

Positive effect against infection exerted by the immune response facilitates viral clearance this is exerted by the primary immune response while the secondary immune response may lead to exaggerated response leading to multiple organ failure, ARDS, and death [2].

Predictors of COVID-19 mortality mainly include elevated cytokine levels or other inflammatory markers [5], so mortality may be related to virally driven-hyper inflammation known as "Cytokine Storm" [3, 4].

Vitamin D (25-hydroxy vitamin D) lately identified as a potential effective drug in the prevention, and treatment of COVID-19 [2].

25 OHD has been epidemiologically linked to many health outcomes [3, 4]. An immunomodulatory role has been found for the vitamin $\mathrm{D}$, so it became a target in COVID-19 management.

Thirty-seven percent of elderly adults in the USA take vit D supplements [6, 7]. Also, it provides a way to lessen burden of the SARS-Cov pandemic.

Some RCTS shown a benefit of 25 OHD supplementation [7]. A meta-analysis of RCTs of 25 OHD supplementation showed benefit in the benign upper respiratory tract and not the lower respiratory tract $(\mathrm{OR}=0.96$; $95 \%$ CI: $0.83,1.10)$ and showed numerically worse all-cause mortality (OR $=1.39 ; 95 \%$ CI: $0.85,2.27)$.

In the pandemic of COVID-19, due to the complexity of the pathophysiology of the disease, and due to the deficiency of supported data this can lead to biased information. One of the debatable issues is the vitamin D role in modulating the severity of COVID-19, as this vitamin has an immunomodulatory functions extending from the innate to the adaptive arms of the immune system including the downregulation of pro-inflammatory cytokines [6].

A lot of clinical and preclinical observations suggested that low vitamin D levels will be in favor of viral infections especially the respiratory tract infections, and the autoimmune disorders [6, 7].

Also, there is a lot of studies shown that vitamin D supplementation protect against respiratory infection $[8,9]$ and there is a strong relation between vitamin $\mathrm{D}$ deficiency [levels below $20 \mathrm{ng} / \mathrm{ml}$ ] and increased risk of progression ad death from viral infections like HIV, because of immune activation, severe inflammation, and monocyte phenotypic activation [9].

An independent relationship become evident from comorbid conditions, this occurs in HIV determining the severity and mortality [10].

The Scientific Advisory Committee on Nutrition (SACN) from UK suggested that there is a benefit from daily low-dose vitamin D. Supplementation (400 to 1000 $\mathrm{Iu} /$ day) in protection from acute respiratory tract infections [11].

So, to strengthen the immune system and to help in fighting against COVID-19, vitamin D plays a great role in that [12].

This concept is supported by recent epidemiological data, suggesting a strong relationship between COVID19 severity and vitamin D deficiency [13-15].

Also there are some reports in patients with or without COVID-19 supporting the previous data [16-22].

It needs to be detected on a prospective way, and it should be taken into consideration whether vitamin $\mathrm{D}$ deficiency or low 25OHD levels, at time of diagnosis, is associated with the severity of COVID-19 and not other confounding factors like age, gender, and major comorbidities. So, a demonstration is required for further support of issuing clinical trials to help in assessing the efficacy of vitamin D level, in patients infected with 
SARS-Cov.2. So, we initiated our study to investigate prospectively in a cohort of COVID-19 patients admitted in our ICU, the relationship between 25OHD levels at ICU admission and severity of COVID-19 and related mortality during the ICU course.

\section{Methods}

Four hundred fourteen COVID-19 patients, diagnosed as a positive result from naso-pharyngeal swab associated with reverse transcription-polymerase chain reaction analysis (Gene X pert, Cepheid, Sunnyvale, USA), were admitted to the ICU with critical COVID-19 pneumonia with acute respiratory failure (spontaneous oxygen saturation $\leq 93 \%$, and/or $\mathrm{PaO}_{2} / \mathrm{FiO}_{2}$ ratio $<300$ $\mathrm{mmHg}$ ) requiring invasive mechanical ventilation, with or without fever and other organ dysfunction in Helwan university hospitals in the period from June 2020 till October 2021. Vitamin $\mathrm{D}_{3}$ level was assayed in all admitted patients with COVID-19 pneumonia in the ICU, and vitamin $\mathrm{D}$ deficiency was defined in each patient with $25 \mathrm{OHD} \leq 60 \mathrm{nmol} / \mathrm{L}$.

All patients were subjected to full laboratory investigations including the cytokine inflammatory markers ferritin, D-Dimer, LDH, CRP, and neutrophil: lymphocyte ratio on admission, on fifth and tenth day of ICU admission, daily arterial blood gas, daily chest X-ray, and chest computed tomography on admission, fifth day, and tenth day from admission.

\section{Ethical approval}

The study was approved by the ethical committee of faculty of Medicine Helwan University. It was conducted in compliance with local regulatory requirements, good clinical practice (GCP), and the Declaration of Helsinki.

\section{Statistics}

The collected data was revised, coded, tabulated and introduced to a pc using statistical package for social science (SPSS 25). Data was presented and suitable analysis was done according to this type of data obtained for each parameter.

\section{Descriptive statistics}

1) Mean, standard deviation ( \pm SD) and range for parameteric numerical data, while median and interquartile range (IQR) for non-parameteric numerical data.

2) Frequency and percentage of non-numerical data.

\section{Analytical statistics}

1) Student's $t$ test was used to assess the statistical significance of the difference between two study group means.

2) Mann-Whitney test ( $U$ test) was used to assess the statistical significance of the difference of a non-parametric variable between two study groups.

3) Correlation analysis (using Pearson's and Spearman's rho methods) to assess the strength of association between two quantitative variables. The correlation coefficient denoted symbolically " $r$ " defines the strength (magnitude) and direction (positive or negative) of the linear relationship between two variables.

- $r=0-0.19$ is regarded as very weak correlation.

- $r=0.2-0.39$ as weak correlation.

- $r=0.40-0.59$ as moderate correlation.

- $r=0.60-0.79$ as strong correlation.

- $R=0.80-1$ as very strong correlation.

4) The ROC curve (receiver operating characteristic) provides a useful way to evaluate the sensitivity and specificity for quantitative diagnostic measures that categorize cases into one of two groups $p$ value: level of significance:

- $P>0.05$ : non-significant (NS).

- $P<0.05$ : significant (S).

\section{Results}

Four hundred and fourteen COVID-19 pneumonia patients admitted to our ICU were enrolled in our clinical trial in the period from June 2020 to October 2021 (Table 1).

Table 2 shows the correlation between vit $\mathrm{D}_{3}$ level and laboratory investigations especially the cytokine storm markers on the fifth and tenth days, which shows a very strong inverse correlation with vitamin $\mathrm{D}_{3}$ level and a highly significant statistical difference. While the cytokine storm markers on admission ferritin, D-dimer, $\mathrm{CRP}, \mathrm{LDH}$, and neutrophil to lymphocytes ratio were

Table 1 Demographic status of the study $(N=414)$

\begin{tabular}{lllll}
\hline & N/Mean & \%/SD & Median (DR) & Range \\
\hline Age & 54.55 & 14.27 & $55(45-64)$ & $(14-97)$ \\
Gender & & & & \\
Male & 285 & $68.8 \%$ & & \\
Female & 129 & $31.2 \%$ & & \\
\hline
\end{tabular}


Table 2 Correlation between vitamin $D_{3}$, laboratory investigations and chest computed tomography

\begin{tabular}{|c|c|c|c|c|c|}
\hline & & Ferritin admission & Ferritin +5 days & Ferritin +10 days & D-dimer admission \\
\hline \multirow[t]{3}{*}{ Vitamin $D_{3}$} & Spearman's rho & -0.015 & -0.739 & -0.885 & -0.046 \\
\hline & Pvalue & 0.758 & $<0.001$ & $<0.001$ & 0.347 \\
\hline & Sig. & NS & H.S. & H.S. & NS \\
\hline D-dimer +5 days & D-dimer +10 days & CRP admission & CRP +5 days & CRP +10 days & LDH admission \\
\hline-0.858 & -0.889 & 0.95 & -0.868 & -0.891 & 0.022 \\
\hline$<0.001$ & $<0.001$ & 0.005 & $<0.001$ & $<0.001$ & 0.661 \\
\hline H.S. & H.S & NS & H.S & H.S & NS \\
\hline $\begin{array}{l}\text { LDH } \\
+5 \text { days }\end{array}$ & $\begin{array}{l}\text { LDH } \\
+10 \text { days }\end{array}$ & $\mathrm{N}: \mathrm{L}$ ratio admission & $\begin{array}{l}N: L \text { ratio } \\
+5 \text { days }\end{array}$ & $\begin{array}{l}N: L \text { ratio } \\
+10 \text { days }\end{array}$ & \\
\hline-0.887 & -0.878 & -0.075 & -0.753 & -0.882 & \\
\hline$<0.001$ & $<0.001$ & 0.26 & $<0.001$ & $<0.001$ & \\
\hline H.S. & H.S. & H.S. & H.S. & H.S. & \\
\hline CT-chest admission & & $\begin{array}{l}\text { CT-chest } \\
+5 \text { days }\end{array}$ & & $\begin{array}{l}\text { CT-chest } \\
+10 \text { days }\end{array}$ & \\
\hline-0.655 & & -0.876 & & -0.916 & \\
\hline 0.05 & & $<0.001$ & & $<0.001$ & \\
\hline S & & H.S. & & H.S. & \\
\hline
\end{tabular}

Table 3 Correlation between vitamin $\mathrm{D}_{3}$ level and mechanical ventilation days

\begin{tabular}{ll}
\hline & MV days \\
\hline Vitamin $D_{3}$ level & \\
Spearman's rho & -0.879 \\
$P$ value & $<0.001$ \\
Sign. & H.S. \\
\hline
\end{tabular}

all non-significant statistically with a very weak correlation. Also, chest computed tomography revealed a strong and very strong inverse correlation with vitamin D level on admission, fifth day and tenth day respectively with a highly significant statistical difference on days five and ten of admission.

Table 3 shows a very strong inverse correlation of MV days and vitamin $\mathrm{D}_{3}$ level with a highly significant statistical value.

Table 4 shows a very strong inverse correlation between vitamin $\mathrm{D}_{3}$ level and length of stay with a highly significant statistical value.

Table 5 shows the relation between vitamin $D_{3}$ level and the destination (outcome) of COVID patients according to vitamin $\mathrm{D}_{3}$ level where in the expired patients, the level of vitamin $\mathrm{D}_{3}$ was low giving a highly significant statistical difference between the expired and the alive outcome.

The ROC curve of vitamin $\mathrm{D}_{3}$ with sensitivity 94.09 and specificity 67.53, cut-off value of vitamin $D_{3}$ to
Table 4 Correlation between vitamin $\mathrm{D}_{3}$ level and length of stay

\begin{tabular}{ll}
\hline & Length of stay \\
\hline Vitamin $D_{3}$ level & \\
Spearman's rho & -0.795 \\
$P$ value & $<0.001$ \\
Sign. & H.S. \\
\hline
\end{tabular}

predict mortality is less than $60 \mathrm{nmol} / \mathrm{L}$. Area under the curve was $0.865,95 \%$ CI $0.828-0.896$ (Table 6).

\section{Discussion}

SARS-Cov. 2 pandemic with its higher morbidity and mortality rates, pushed us to study the actual mechanisms leading to the poor clinical outcomes in the trial to find effective treatments [1].

For that 25OHD was measured for assaying its levels in a series of SARS-Cov-2-infected patients with severely symptomatic COVID-19 cases who admitted to the ICU with respiratory failure.

For patients who deteriorated and did not improve, the vitamin in $\mathrm{D}_{3}$ level was low leading to long length of stay, prolonged period of mechanical ventilation days, and ending by death while patients with normal level or mild deficiency improved along the ICU course with improving cytokine storm markers, also clinically through the evaluation done on the fifth and tenth days of ICU stay, leading to less duration of ICU stay, mechanical ventilation days and at the end they survived. This over all data matches with similar studies done previously [16-22], 
Table 5 Relation between vitamin $\mathrm{D}_{3}$ level and destination

\begin{tabular}{|c|c|c|c|c|c|}
\hline & \multicolumn{2}{|c|}{ Vitamin $D_{3}$ level } & \multicolumn{3}{|c|}{ Student's $t$ test } \\
\hline & Mean + SD & Median (I Q R) & $\mathbf{T}$ & $p$ value & Sign. \\
\hline \multicolumn{6}{|l|}{ Destination } \\
\hline Expired & $58.25+24.59$ & $54(44-65)$ & -15.195 & $<0.001$ & H.S. \\
\hline Discharged alive & $103.97 \pm 36.14$ & $107.5(74-132)$ & & & \\
\hline
\end{tabular}

Table 6 Receiver operator characteristic curve of vitamin $D_{3}$ to predict mortality

\begin{tabular}{llllll}
\hline AUC & $\mathbf{9 5 \%} \mathbf{C l}$ & Sign. & Cut-off value & Sensitivity & Specificity \\
\hline 0.865 & $0.828-0.896$ & $<0.001$ & $<60$ & 94.09 & 67.53 \\
$+\mathrm{LR}$ & $-\mathrm{LR}$ & $+\mathrm{PV}$ & $-\mathrm{PV}$ & & \\
2.9 & 0.088 & 76.7 & 91 & & \\
\hline
\end{tabular}

and emphasis on that vitamin D deficiency is independently associated with the clinical outcome of COVID-19 patients away from age or other comorbidities commonly detected in admitted COVID-19 patients.

A possible correlation was suggested in many different studies between vitamin $\mathrm{D}_{3}$ levels and COVID-19 on indirect proofs like the risk of SARS-COV 2 infection and its spread [14] or the inverse correlation between vitamin $\mathrm{D}_{3}$ levels mean and the number of infected cases in Europe [15]. Many large observational studies, and also cohort studies found significantly lower levels of 25OHD in COVID-19 patients when compared with negative cases of COVID, suggesting a strong relation between low 25 OHD levels and COVID-19 positivity [23-26].

The results of our study are in line with all previous observational studies. Suggesting that low level of 25OHD levels may lead to infection with SARS-Cov-2 and leads to risk of severe respiratory failure and mortality during the ICU course in patients affected by SARS-Cov-2.

There is a strong inverse correlation between vitamin $\mathrm{D}$ level and the cytokine storm inflammatory markers like ferritin, D-dimer, CRP, LDH, and neutrophil to lymphocyte ratio especially in the fifth and tenth days of the ICU course of patients affected by COVID-19 [27-29].

Low vitamin D is associated with increased inflammatory reaction in patients taking bisphosphonate and became more evident when vitamin $\mathrm{D}$ level is below 60 $\mathrm{nmol} / \mathrm{L}[30]$.

Experimental studies found that, vitamin D locally activated in lung tissues and leads to beneficial effect on interstitial pneumonia experimentally [31, 32].

Also many mechanisms can be involved in the protection of lung tissue like modulation of neutrophil activity by decreasing their activation and penetration into the lung tissue, so decreasing alveolar damage, it can also occur by suppressing all the pro-inflammatory cytokines, also activation of cathelicidin and defesins which can destruct the virus itself $[7,15]$.

In Experimental animals vitamin D maintain, the pulmonary vascular barrier from jury by inflammatory process by affecting the renin angiotensin system [33], which can lead to invasion of the alveolar cells by the COVID19 virus with activation of inflammatory cytokines and occurrence of ARDS [2, 34].

Vitamin D also plays a major role in activation of surfactant synthesis, improving alveolar surface tension, protecting against inflammation, and decreasing oxidative stress [35].

So, normal vitamin D can improve clinical outcome of SARS-Cov-2 by maintaining pulmonary vascular barrier and aborting the release of the inflammatory cytokine storm markers.

From the epidemiological data it shows that death from SARS-Cov-2 infection was more in the countries which has more winter time because vitamin D deficiency is more prominent in winter season and because of lack of supplementation policies [36].

In the start of pandemic, in the first quarter of the year 2020, there is a larger spread in the northern hemisphere along the $30-50^{\circ} \mathrm{N}$ latitude zone while it was less by around $2-6 \%$ in the courtiers below the $37^{\circ} \mathrm{N}$ parallel [37] because of good sun exposure leading to adequate 25 OHD levels even if there is fall or in winter time [6], and so death rate was lower in those countries.

Also, flows of the pandemic in the northern countries showed an increase in mortality starting from the last three months of 2020 as it is winter time; US SARSCov- 2 mortality was 4-5 times more among black citizen patients, whom generally have lower vitamin $\mathrm{D}$ concentration than other citizens $[38,39]$.

Vitamin D levels were higher in the surviving patients who experienced COVID-19 even if they experienced mechanical ventilation and ARDS in comparing with those who died as their vitamin D levels were very low; also cytokine storm markers starts to regress starting from fifth and tenth day post-ICU admission giving a very strong inverse correlation with the vitamin D level 
in the surviving patients leading to clinical improvement and weaning from mechanical ventilation.

Vitamin D levels found in many studies to be low in severely symptomatic COVID-19 patients which can be considered as an acute phase reactant and can decrease with the severity of the disease (https://www.aifa.gov. it/-/vitamina-d-consumi-e-spesa-ridotti-dall-introduzio ne-della-nota-96), [40-43], which also was confirmed in many observational studies where they found a strong relation between 25 OHD levels and the severity of SARS-Cov-2 [26, 44-46].

Also, recent data from UK Biobank, where 1082 SARSCov-2 patients were included showing a strong relationship between vitamin $\mathrm{D}$ level and severity of the case of COVID-19-affected patients [47-49].

All the previous studies confirmed the results of our study that the level of vitamin D is very strongly inverse correlated with the severity of the case of COVID-19 as regards the cytokine storm markers which was followed along the ICU course in the fifth and tenth days, and improved in the surviving patients leading to less mechanical ventilation days and less length of stay.

\section{Conclusion}

Vitamin D levels plays a crucial role in increasing or decreasing the level of the cytokines storm inflammatory markers according to the actual level of vitamin D; if there is deficiency and the level is low, the cytokine storm inflammatory markers are high and patient experiences a severely symptomatic COVID-19 affection and becomes an independent predictor of mortality other than any co-morbidities and can be a prognostic marker of the severity of the COVID-19-diseased patients, so vitamin D supplementation during the course of COVID-19-affected patients can affect the progression of the severity of the disease [50-56].

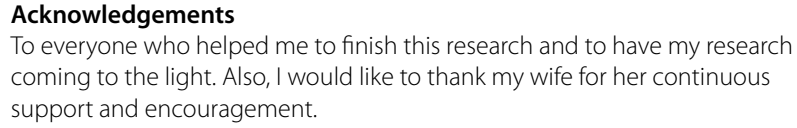

Authors' contributions

MS, AM, and AO read and approved the final manuscript.

\section{Funding}

No funding.

\section{Availability of data and materials}

Available upon request.

\section{Declarations}

Ethics approval and consent to participate

All taken and available.

\section{Consent for publication}

Available.

\section{Competing interests}

All authors declare that they have no competing interests.

\section{Author details}

${ }^{1}$ Critical Care Medicine Department, Faculty of Medicine Helwan University, Helwan, Egypt. ${ }^{2}$ Clinical Pharmacy Department, Helwan University Hospitals, Helwan, Egypt. ${ }^{3}$ Nursing Department Helwan University Hospitals, Helwan, Egypt.

Received: 23 November 2021 Accepted: 28 January 2022

Published online: 21 February 2022

\section{References}

1. Cook DJ, Marshall JC, Fowler RA (2020) Critical illness in patients with COVID-19: mounting an effective clinical and research response. JAMA 323(16):1559-1560. https://doi.org/10.1001/jama.2020.5775

2. Sarzi-Puttini P, Giorgi V, Sirotti S, Marotto D, Ardizzone S, Rizzardini G et al (2020) COVID-19, cytokines and immunosuppression: what can we learn from severe acute respiratory syndrome? Clin Exp Rheumatol 38:337

3. Mehta P, McAuley DF, Brown M, Sanchez E, Tattersall RS, Manson JJ, HLH Across Speciality collaboration, UK (2020) HLH across specialty collaboration, UK COVID-19: consider cytokine storm syndromes and immunosuppression. Lancet 395(10229):1033-1034. https://doi.org/10.1016/SO1406736(20)30628-0

4. McGonagle D, Sharif K, O'Regan A, Bridgewood C (2020) The role of cytokines including Interleukin-6 in COVID-19 induced pneumonia and macrophage activation syndrome-like disease. Autoimmun Rev 19:102537. https://doi.org/10.1016/j.autrev.2020.102537

5. Cummings MJ, Baldwin MR, Abrams D, Jacobson SD, Meyer BJ, Balough EM (2020) Epidemiology, clinical course, and outcomes of critically ill adults with COVTD-19 in New York city: a prospective cohort study. Lancet 395(10239):1763-1770. https://doi.org/10.1016/S0140-6736(20) $31189-2$

6. Bouillon R, Marcocci C, Carmeliet G, White JH, Dawson-Hughes B, Lips P et al (2019) Skeletal and extraskeletal actions of vitamin D: current evidence and outstanding questions. Endocr Rev 40(4):1109-1151. https:// doi.org/10.1210/er.2018-00126

7. Quesada-Gomez JM, Entrenas-Castillo M, Bouillon R (2020) Vitamin D receptor stimulation to reduce acute respiratory distress syndrome (ARDS) in patients with coronavirus SARS-CoV-2 infections, revised Ms SBMB 2020-166. J Steroid Biochem Mol Biol 202:105719. https://doi.org/ 10.1016/j.jsbmb.2020.105719

8. Martineau AR, Jolliffe DA, Hooper RL, Greenberg L, Aloia JF, Bergman P et al (2017) Vitamin D supplementation to prevent acute respiratory tract infections: systematic review and meta-analysis of individual participant data. Br Med J 356:16583. https://doi.org/10.1136/bmj.i6583

9. Jolliffe DA, Camargo CA Jr, Sluyter JD, Aglipay M, Aloia JF, Ganmaa D et al (2021) Vitamin D supplementation to prevent acute respiratory infections: a systematic review and meta-analysis of aggregate data from randomised controlled trials. Lancet Diabetes Endocrinol S2213_8587(21):00051-00056. https://doi.org/10.1016/S2213-8587(21)00051-6

10. Havers F, Smeaton L, Gupte N, Detrick B, Bollinger RC, Hakim J, Kumarasamy N, Andrade A, Christian P, Lama JR, Campbell TB, Gupta A, ACTG PEARLS. (2014) NWCS 319 Study Teams 25- Hydroxyvitamin D insufficiency and deficiency is associated with HIV disease progression and virological failure post-antiretroviral therapy initiation in diverse multinational settings. J Infect Dis 210(2):244-253. https://doi.org/10.1093/infdis/jiu259

11. The Scientific Advisory Committee on Nutrition (SACN) rapid review on vitamin D and acute respiratory tract infections (ARTI). 2020. https:// www.gov.uk/govemment/publications/sacn-rapid-review-vitamin-dand-acute-respiratory-tract-infections.

12. Mitchell F (2020) Vitamin-D and COVID-19: do deficient risk a poorer outcome? Lancet Diabetes Endocrinol 8(7):570. https://doi.org/10.1016/ S2213-8587(20)30183-2

13. Grant WB, Lahore H, McDonnell SL, Baggerly CA, French CB, Aliano JL et al (2020) Evidence that vitamin D supplementation could reduce risk of influenza and COVID-19 infections and deaths. Nutrients 12(4):988. https://doi.org/10.3390/nul2040988 
14. Rhodes JM, Subramanian S, Laird E, Kenny RA (2020) Editorial: low population mortality from COVID-19 in countries south of latitude 35 degrees north supports vitamin D as a factor determining severity. Aliment Pharmacol Ther 51(12):1434-1437. https://doi.org/10.1111/apt.15777

15. Ilie PC, Stefanescu S, Smith L (2020) The role of vitamin D in the prevention of coronavirus disease 2019 infection and mortality. Aging Clin Exp Res 32(7):1195-1198. https://doi.org/10.1007/s40520-020-01570-8

16. Panagiotou G, Tee SA, Ihsan Y, Athar W, Marchitelli G, Kelly D, Boot CS, Stock N, Macfarlane J, Martineau AR, Brans G, Quinton R (2020) Low serum 25-hydroxyvitamin D (25[OH]D) levels in patients hospitalised with COVID-19 are associated with greater disease severity. Clin Endocrinol 93(4):508-511. https://doi.org/10.1111/cen.14276

17. Hars M, Mendes A, Serratrice C, Herrmann FR, Gold G, Graf C et al (2020) Sex-specific association between vitamin D deficiency and COVID-19 mortality in older patients. Osteoporos Int 13:1

18. Radujkovic A, Hippchen T, Tiwari-Heckler S, Dreher S, Boxberger M, Merle U (2020) Vitamin D deficiency and outcome of COVID-19 patients. Nutriments 12(9):2757. https://doi.org/10.3390/nu12092757

19. De Smet D, De Smet K, Herroelen P, Gryspeerdt S, Martens GA (2021) Serum 25(OH)D level on admission associated with COVID-19 stage and mortality. Am J Clin Pathol 155(3):381. https://doi.org/10.1093/ajcp/aqaa2 52

20. Hernandez JL, Nan D, Fernandez-Ayala M, Garcia-Unzueta M, HernándezHemández MA, López- Hoyos M, Munoz-Cacho P, Olmos JM, GutiérrezCuadra M, Ruiz-Cubilldn JJ, Crespo J, Martinez-Taboada VM (2021) Vitamin D Status in hospitalized patients with SSARS-CoV-2 infection. J Clin Endoocrinol Metab 106(3):e1343-e1353. https://doi.org/10.1210/clinem/ dgaa733

21. Merzon E, Tworowski D, Gorohovski A, Vinker S, Golan Cohen A, Green I, Frenkel-Morgenstern M (2020) Low plasma $25(\mathrm{OH})$ vitamin D level is associated with increased risk of COVID-19 infection: an Israeli population-based study. FEBS J 287(17):3693-3702. https://doi.org/10.1111/febs. 15495

22. Maghbooli Z, Sahraian MA, Ebrahimi M, Pazoki M, Kafan S, Tabriz HM, Hadadi A, Montazeri M, Nasiri M, Shirvani A, Holick MF (2020) Vitamin D sufficiency, a serum 25 -hydroxyvitamm $D$ at least $\mathrm{ng} / \mathrm{mL}$ reduced risk for adverse clinical outcomes in patients with COVID-19 infection. PLoS One 15(9):e0239799. https://doi.org/10.1371/joumal.pone.0239799

23. Duca A, Piva S, Focà E, Latronico N, Rizzi M (2020) Calculated decisions: Brescia-COVID Respiratory Severity Scale (BCRSS)/Algorithm. Emerg Med Pract 22:CD1-CD2

24. Zou G (2004) A modified poisson regression approach to prospective studies with binary data. Am J Epidemiol 159(7):702-706. https://doi.org/ 10.1093/aje/kwh090

25. Kaufman HW, Niles JK, Kroll MH, Bi C, Holick MF (2020) SARS-CoV-2 positivity rates associated with circulating 25 -hydroxyvitamin D levels. PLoS One 15:1-10

26. Meltzer DO, Best TJ, Thang H, Vokes T, Arora V, Solway J (2020) Association of vitamin D status and other clinical characteristics with COVID-19 test results. JAMA Netw Open 3(9):e2019722. https://doi.org/10.1001/jaman etworkopen2020.19722

27. Xu X, Han M, LiT, Wang D, Fu B, Zhou Y (2020) Effective treatment of severe COVID-19 patients with tocilizumab. Proc Natl Acad Sci USA 17:10970. https://doi.org/10.1073/pnas.2005615117

28. Capra R, De Rossi N, Mattioli F, Romanelli G, Scarpazza C, Sormani MP et al (2020) Impact of low dose tocilizumab on mortality rate in patients with COVID-19 related pneumonia. EurJ Intern Med 76:31-35. https://doi.org/ 10.1016/j.ejim.2020.05.009

29. Ghosn L, Chaimani A, Evrenoglou T, Davidson M, Grana C, Schmucker C et al (2021) Interleukin-6 blocking agents for treating COVID-19: a living systematic review. Cochrane Database Syst Rev 3:CD013881

30. Merlotti D, Rendina D, Muscariello R, Picchioni T, Alessandri M, De Filippo $G$ et al (2020) Preventive role of vitamin D supplementation for acute phase reaction after bisphosphonate infusion in Paget's disease. J Clin Endocrinol Metab 105:466. https://doi.org/10.1210/clinem/dgz1387

31. Sliberstein M (2021) COVID-19 and IL-6: why vitamin D (probably) helps but tocilizumab might not. Euyr J Pharmacol 899(17403):1. https://doi. org/10.1016/j.ejphar.2021.174031

32. Tsujino I, Ushikoshi-Nakayama R, Yamazakj T, Matsumoto N, Saito I (2019) Pulmonary activation of vitamin $D_{3}$ and preventive effect against interstitial pneumonia. J Clin Biochem Nutr 65(3):245-251. https://doi. org/10.3164/jcbn.19-48

33. Kong J, Zhu X, Shi Y, Liu T, Chen Y, Bhan I, Zhao Q, Thadhani R, Li YC (2013) VDR attenuates acute lung injury by blocking Ang-2-Tie-2 pathway and renin-angiotensin system. Mol Endocrinol 27(12):2116-2125. https://doi. org/10.1210/me.2013-1146

34. Hoffmann M, Kleine-Weber H, Schroeder S, Kruger N, Herrler T, Erichsen S, Schiergens TS, Herrler G, Wu NH, Nitsche A, Muller MA, Drosten C, Pohlmann S (2020) SARS-CoV-2 cell entry depends on ACE2 and TMPRSS2 and is blocked by a clinically proven protease inhibitor. Cell 181(2):271280.e8. https://doi.org/10.1016/j.cell.2020.02.052

35. Phokela SS, Peleg S, Moya FR, Alcorn JL (2005) Regulation of human pulmonary surfactant protein gene expression by lalpha,25- dihydroxyvitamin D3. Am J Physiol Lung Cell Mol Physiol 289:617. https://doi.org/10. 1152/ajplung.00129.2004

36. Lips $P$, Cashman KD, Lamberg-Allardt C, Bischoff-Ferrari HA, ObermayerPietsch B, Bianchi ML et al (2019) Current vitamin D status in European and Middle East countries and strategies to prevent vitamin D deficiency: a position statement of the European calcified tissue society. Eur J Endocrinol 180:P23. https://doi.org/10.1530/EJE-18-0736

37. COVID-19 Dashboard by the Center for Systems Science and Engineering (CSSE) at Johns Hopkins University. https://coronavirus.ihu.edu/map.html.

38. Coronavirus (COVID-19) health alert. Australian Government, Department of Health. https://www.health.gov.au/resources/collections/coronaviruscovid-19-at-a-glance-infographic-collection\#collection-description.

39. The Color of Coronavirus: COVID-19 deaths by race and ethnicity in the U.S. https://www.apmresearchlab.org/covid/deaths-bv-race\#black.

40. https://www.aifa.gov.it/-/vitamina-d-consumi-e-spesa-ridotti-dall-intro duzione-della-nota-96.

41. Bouillon R, Schuit F, Antonio L, Rastinejad F (2020) Vitamin D binding protein: a historic overview. Front Endocrinol (Lausanne) 10:e910. https:// doi.org/10.3389/fendo.2019.00910

42. Reid D, Knox S, Talwar D, O'Reilly DJ, Blackwell S, Kinsella J et al (2010) Acute changes in the systemic inflammatory response is associated with transient decreases in circulating 25- hydroxyvitamin D concentrations following elective knee arthoplasty. Ann Clin Biochem 47(Suppl 1):95-96

43. Louw JA, Werbeck A, Louw ME, Kotze TJ, Cooper R, Labadarios D (1992) Blood vitamin concentrations during the acute-phase response. Crit Care Med 20(7):934-41.3. https://doi.org/10.1097/00003246-199207000-00007

44. Charoenngam N, Shirvani A, Reddy N, Vodopivec DM, Apovian CM, Holick MF (2021) Association of vitamin D status with hospital morbidity and mortality in adult hospitalized patients with COVID-19. Endocr Pract 27(4):271-278. https://doi.org/10.1016/j.eprac.2021.02.013

45. Demir M, Demir F, Aygun H (2021) Vitamin D deficiency is associated with COVID-19 positivity and severity of the disease. J Med Virol 93(5):29922999. https://doi.org/10.1002/jmv.26832

46. Li S, Cao Z, Yang H, Zhang Y, Xu F, Wang Y (2021) Metbolic healthy obesity, vitamin D status, and risk of COVID-19. Aging Dis 12(1):61-71. https://doi. org/10.14336/AD.2020.1108

47. Hastie CE, Mackay DF, Ho F, Celis-Morales CA, Katikireddi SV, Niedzwiedz CL, Jani BD, Welsh P, Mair FS, Gray SR, O'Donnell CA, Gill JMR, Sattar N, Pell JP (2020) Vitamin D concentrations and COVID-19 infection in UK biobank. Diabetes Metab Syndr 14(4):561-565. https://doi.org/10.1016/j. dsx.2020.04.050

48. Raisi-Estabragh Z, McCracken C, Bethell MS, Cooper J, Cooper C, Caulfield MJ et al (2020) Greater risk of severe COVID-19 in Black, Asian and Minority Ethnic populations is not explained by cardiometabolic, socioeconomic or behavioural factors, or by $25(\mathrm{OH})$-vitamin D status: study of 1326 cases from the UK Biobank. J Public Health (Oxf) 42:451-460. https://doi.org/10.1093/pubmed/fdaa095

49. Hastie CE, Pell JP, Sattar N (2020) Vitamin D and COVID-19 infection and mortality in UK biobank. Eur JNutr 60:545-548. https://doi.org/10.1007/ s00394-020-02372-4

50. Bouillon R (2020) Safety of high-dose vitamin D supplementation. J Clin Endocrinol Metab 105:dgz282. https://doi.org/10.1210/clinem/dgz282

51. Camargo CA Jr, Martineau AR (2020) Vitamin D to prevent COVID-19: recommendations for the design of clinical trials. FEBS J 287(17):3689-3692. https://doi.org/10.1111/febs.15534

52. Entrenas Castillo M, Entrenas Costa LM, Vaquero Barrios JM, Alcala Diaz JF, Lopez Miranda J, Bouillon R, Quesada Gomez JM (2020) Effect of calcifediol treatment and best available therapy versus best available therapy 
on intensive care unit admission and mortality among patients hospitalized for COVID-19: a pilot randomized clinical study. J Steroid Biochem Mol Biol 203:105751. https://doi.org/10.1016/j.jsbmb.2020.105751

53. Cangiano B, Fatti LM, Danesi L, Gazzano G, Croci M, Vitale G et al (2020) Mortality in an Italian nursing home during COVID-19 pandemic: correlation with gender, age, $A D L$, vitamin $D$ supplementation, and limitations of the diagnostic tests. Aging (Albany NY) 12(24):24522-24534. https:// doi.org/10.18632/aging.202307

54. Annweiler G, Corvaisier M, Gautier J, Dubee V, Legrand E, Sacco G, Annweiler C (2020) Vitamin D supplementation associated to better survival in hospitalized frail elderly COVID-19 patients: the GERIA-COVID quasiexperimental study. Nutrients 12(11):3377. https://doi.org/10.3390/nul21 13377

55. Rastogi A, Bhansali A, Khare N, Suri V, Yaddanapudi N, Sachdeva N et al (2020) Short term, high-dose vitamin D supplementation for COVID19 disease: a randomised, placebo-controlled, study (SHADE study). Postgrad Med J. 2020:139065. https://doi.org/10.1136/postgradme dj-2020-139065.

56. Murai IH, Fernandes AL, Sales LP, Pinto AJ, Goessler KF, Duran CSC, Silva CBR, Franco AS, Macedo MB, Dalmolin HHH, Baggio J, Balbi GGM, Reis BZ, Antonangelo L, Caparbo VF, Gualano B, Pereira RMR (2021) Effect of a single high dose of vitamin D3 on hospital length of stay in patients with moderate to severe COVID-19: a randomized clinical trial. JAMA 325(11):1053-1060. https://doi.org/10.1001/jama.2020.26848

\section{Publisher's Note}

Springer Nature remains neutral with regard to jurisdictional claims in published maps and institutional affiliations.

\section{Submit your manuscript to a SpringerOpen ${ }^{\circ}$ journal and benefit from:}

- Convenient online submission

- Rigorous peer review

- Open access: articles freely available online

- High visibility within the field

- Retaining the copyright to your article

Submit your next manuscript at $\boldsymbol{\nabla}$ springeropen.com 